\title{
The "Lung": a software-controlled air accumulator for quasi-continuous multi-point measurement of agricultural greenhouse gases
}

\author{
R. J. Martin ${ }^{1}$, A. M. Bromley ${ }^{1}$, M. J. Harvey ${ }^{1}$, R. C. Moss ${ }^{1}$, E. Pattey ${ }^{2}$, and D. Dow ${ }^{2}$ \\ ${ }^{1}$ National Institute of Water and Atmospheric Research, P.O. Box 14-901, Kilbirnie, Wellington, New Zealand \\ ${ }^{2}$ Agriculture and Agri-Food Canada, 960 Carling Ave, Ottawa, Ontario K1A 0C6, Canada
}

Received: 13 December 2010 - Published in Atmos. Meas. Tech. Discuss.: 21 March 2011

Revised: 5 July 2011 - Accepted: 13 September 2011 - Published: 21 October 2011

\begin{abstract}
We describe the design and testing of a flexible bag ("Lung") accumulator attached to a gas chromatographic (GC) analyzer capable of measuring surface-atmosphere greenhouse gas exchange fluxes in a wide range of environmental/agricultural settings. In the design presented here, the Lung can collect up to three gas samples concurrently, each accumulated into a Tedlar bag over a period of $20 \mathrm{~min}$ or longer. Toggling collection between 2 sets of 3 bags enables quasi-continuous collection with sequential analysis and discarding of sample residues. The Lung thus provides a flexible "front end" collection system for interfacing to a GC or alternative analyzer and has been used in 2 main types of application. Firstly, it has been applied to micrometeorological assessment of paddock-scale $\mathrm{N}_{2} \mathrm{O}$ fluxes, discussed here. Secondly, it has been used for the automation of concurrent emission assessment from three sheep housed in metabolic crates with gas tracer addition and sampling multiplexed to a single GC.

The Lung allows the same GC equipment used in laboratory discrete sample analysis to be deployed for continuous field measurement. Continuity of measurement enables spatially-averaged $\mathrm{N}_{2} \mathrm{O}$ fluxes in particular to be determined with greater accuracy, given the highly heterogeneous and episodic nature of $\mathrm{N}_{2} \mathrm{O}$ emissions. We present a detailed evaluation of the micrometeorological flux estimation alongside an independent tuneable diode laser system, reporting excellent agreement between flux estimates based on down-
\end{abstract}

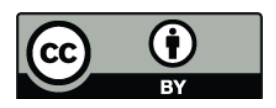

Correspondence to: R. J. Martin (r.martin@niwa.co.nz) wind vertical concentration differences. Whilst the current design is based around triplet bag sets, the basic design could be scaled up to a larger number of inlets or bags and less frequent analysis (longer accumulation times) where a greater number of sampling points are required.

\section{Introduction}

Globally the agriculture sector accounts for about $10-12 \%$ of total global $\mathrm{CO}_{2}$ equivalent $\left(\mathrm{CO}_{2}\right.$-e) emissions of anthropogenic greenhouse gases (Smith et al., 2007). Specifically, agricultural non- $\mathrm{CO}_{2}$ emissions account for about half of the all anthropogenic methane $\left(\mathrm{CH}_{4}\right)$ and $60 \%$ of the anthropogenic nitrous oxide $\left(\mathrm{N}_{2} \mathrm{O}\right)$. New Zealand has a strong agricultural sector accounting for about half of its total export economy with pastoral agriculture (dairy, meat and wool) accounting for about three quarters of the agriculture sector exports (Statistics New Zealand, 2009). As a consequence, New Zealand has the highest proportion of agricultural sector non- $\mathrm{CO}_{2}$ greenhouse gas emissions amongst the developed countries. In the New Zealand national greenhouse gas inventory (Ministry for the Environment, 2010) $\mathrm{CH}_{4}$ accounts for $35 \%$ of the national total, and $\mathrm{N}_{2} \mathrm{O} 16 \%$, i.e. non- $\mathrm{CO}_{2}$ gases account for $51 \%$ of total $\mathrm{CO}_{2}$-e emissions. Agricultural activities account for $90 \%$ and $96 \%$ of the $\mathrm{CH}_{4}$ and $\mathrm{N}_{2} \mathrm{O}$, respectively, or $47 \%$ of the national $\mathrm{CO}_{2}$-e emission. With the unique importance of agricultural emissions in New Zealand's greenhouse gas profile and in the light of New Zealand's obligations under the Kyoto Protocol, there is an obligation to develop mitigation strategies, and a need to

Published by Copernicus Publications on behalf of the European Geosciences Union. 
develop measurement techniques that will improve the quality of emission estimates and provide accurate verification of emission mitigation measures.

For ruminant methane, a technique using a $\mathrm{SF}_{6}$ tracer source placed in individual animal rumina has been developed and used to quantify emissions from free-grazing animals (Johnson et al., 1994; Lassey et al., 1997). At the paddock/herd scale, micrometeorological techniques have been deployed alone or in combination with tracer release (Laubach et al., 2008; Griffith et al., 2008). Recently, some concerns around the behaviour of intra-ruminal permeation tubes and the released $\mathrm{SF}_{6}$ (Pinares-Patiño and Clark, 2008; Pinares-Patino et al., 2008) have led to a detailed examination of the technique under controlled conditions (Lassey et al., 2011).

In order to understand and measure $\mathrm{N}_{2} \mathrm{O}$ emissions from agricultural soils, researchers commonly use chamber techniques to measure gas fluxes directly from the soil. This approach provides a sound basis for developing models to screen potential mitigation practices for reducing greenhouse gas (GHG) emissions within experimental treatment plots. However, there are limitations with using the chamber technique for quantifying nitrous oxide emission from pastoral agriculture because:

1. in animal grazing systems, more than half of the nitrogen deposition comes from animal excreta and the emissions are spatially variable due to the patchiness of urine nitrogen deposition in the paddock. Representative spatial integration is hard to achieve with small chambers (usually $<1 \mathrm{~m}^{2}$ per chamber);

2. the emissions are episodic and protracted. Static chamber measurements are labour intensive and rarely provide the continuous measurements required for integrating the flux over time. For example, Pattey et al. (2006) have shown that an overestimation of $\mathrm{N}_{2} \mathrm{O}$ flux could result from measuring only once daily and that capturing the contribution of $\mathrm{N}_{2} \mathrm{O}$ emission fluctuations would require sampling several times at evenly spaced intervals during each day. In practice, this requires automated chambers. Where emissions are highly episodic, i.e. a significant portion of the emission occurs in short bursts (Harvey et al., 2008), then there is a high probability that chamber sampling will under-estimate emissions when up-scaled. A more detailed assessment has been made by Parkin (2008) of the influence of non-continuous chamber measurement on the measured flux;

3. chambers are intrusive; i.e. they modify the environment, intercepting light and wind, and modifying ground temperature. For instance Davidson et al. (2002) found the build up of gas in the chamber headspace will affect the diffusion gradient in the soil below and is likely to lead to an increasing underestimate of the flux as time progresses. Livingston et al. (2005) found that chambers typically underestimate emission rates by $15-$ $25 \%$ through ignoring this effect. Suleau et al. (2009) discuss how to minimize significant errors that can occur with pressure differences between the chamber atmosphere and ambient environment.

Tower-based micrometeorological techniques offer the advantage of measuring spatially integrated GHG fluxes nonintrusively and almost continuously (Pattey et al., 2006). Techniques such as the flux-gradient, relaxed eddy accumulation or integrated horizontal flux measurement can be used to determine $\mathrm{N}_{2} \mathrm{O}$ or $\mathrm{CH}_{4}$ fluxes from a diffuse source (Denmead, 2008). Possibilities for more direct eddy covariance measurement of methane source/sink fluxes have recently become evident through the development of sensitive fast response instrumentation such as cavity laser spectroscopy for methane (Eugster and Plüss, 2010) and tunable diode laser for nitrous oxide (Pihlatie et al., 2005) and quantum cascade laser for methane and nitrous oxide (Kroon et al., 2010). Many previous chamber studies of GHG fluxes use laboratory based gas chromatographs (GCs) with vial autosamplers to determine $\mathrm{CH}_{4}, \mathrm{~N}_{2} \mathrm{O}$ and $\mathrm{CO}_{2}$ mixing ratios in discrete air samples extracted, typically by syringe, from chamber headspaces.

Here we describe the development of a flexible bag accumulator (the "Lung") which when coupled to a GC ("LungGC system") and with an instrumented mast can measure GHG vertical profiles in close to real time. These continuous measurements are used to infer continuous GHG fluxes at the paddock scale. An important feature of the Lung-GC system is that simultaneous automated flux measurements of $\mathrm{CH}_{4}, \mathrm{~N}_{2} \mathrm{O}$ and $\mathrm{CO}_{2}$ can be made in real time using the same GC equipment that is used for chamber studies, thereby minimising investment in new equipment. Such measurements provide a quasi-continuous record of target-gas composition at the sampling site more cost-effectively than practical deployment of static chambers followed by laboratory analysis, even when the latter uses a gas-bench autosampler. Section 2 describes the design and operation of the Lung. A detailed assessment of its precision was made in comparison with an independently calibrated tuneable-diode laser (TDL) gas-flux measurement system, illustrating its reliability and ease of operation under field experiment conditions (Sect. 3). Results are presented from a validation experiment carried out on a dairy farm grazed by a herd of $\sim 700$ dairy cows. Finally, other applications are discussed (Sect. 4)

\section{Design and operation of the Lung}

\subsection{Conceptual Lung design}

The Lung is designed to accumulate concurrent air samples from up to three collection points such as individual flux chambers or fixed levels on a micrometeorological mast, and 


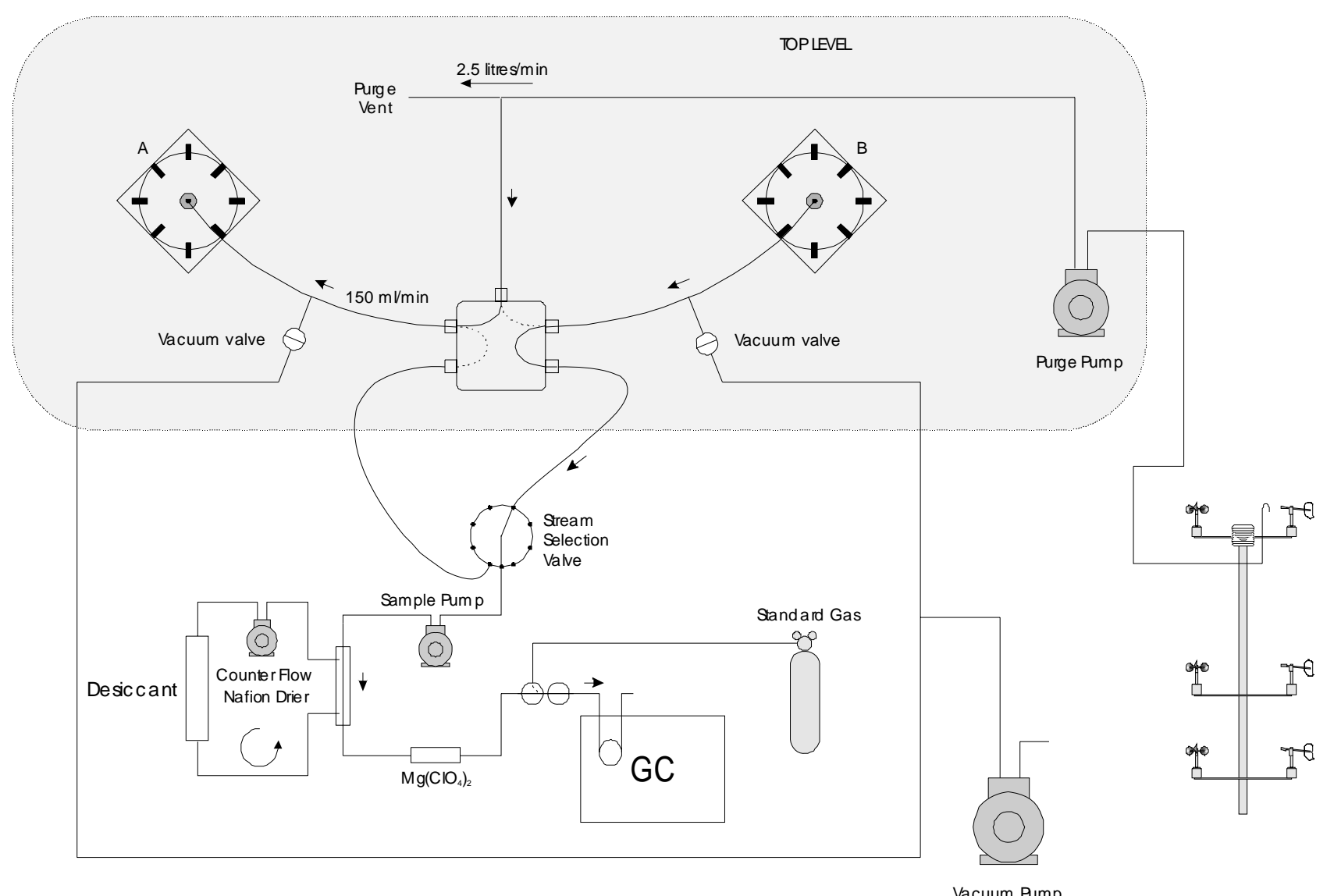

Fig. 1. A schematic of the Lung-GC system interfacing up to three inlets (shown as one sampling point on a micrometeorological mast). A purge pump for each airline maintains the flow between the sample inlets and the laboratory. In practice, sample inlets can be up to $200 \mathrm{~m}$ away from the laboratory. While Cluster A is being filled, a sample is drawn from Cluster B, dried, and directed to the GC. When all the bags in Cluster B have been analysed they are evacuated and the cluster roles are reversed. Three 5 port valves (one per layer), one of which is depicted near the centre of the figure, switch simultaneously to control the role reversal.

then measure sequentially the target GHG's such as $\mathrm{N}_{2} \mathrm{O}$, $\mathrm{CO}_{2} \mathrm{CH}_{4}$ and $\mathrm{SF}_{6}$, using gas chromatography or an alternative analyser. By sampling continuously (i.e. with no gaps between accumulations) a quasi-continuous compositional record is acquired. The Lung-GC system comprises three main components: (1) up to three inlets (collection points); (2) a fully automated bag sampling unit; and (3) a gas chromatograph (GC). Precise timing and control are maintained by a LabVIEW application which fully automates the collection, gas analysis and preparation of the bags for the next sample. The gas collection is made through three $6 \mathrm{~mm}$ OD polyethylene airlines (Leda Industries, New Zealand) between gas inlets and a field laboratory. For micrometeorological applications, the inlets would typically be at elevations on a mast, commonly less than $3 \mathrm{~m}$ above ground level.

The Lung-GC configuration is illustrated in Fig. 1. Air sample line lengths up to $200 \mathrm{~m}$ have been used successfully. Sampling lines are the same length to keep flow times as close to identical as possible. Each line is purged continuously at $2.51 \mathrm{~min}^{-1}$ with an individual small 12 volt pump (NMP830KVDC, KNF, Germany) and run off to waste. The small overpressure developed near the purge vent is used to direct a smaller sample flow of $150 \mathrm{ml} \mathrm{min}^{-1}$ into one of a cluster of 51 Tedlar bags, (Alltech part \#41059), each being associated with a single sample inlet. This flow is controlled by adding a short length of restrictive tube to the purge vent. Varying the length or bore of this tube adjusts the rate at which a cluster of bags are filled. In this case, 31 of air is collected over a $20 \mathrm{~min}$ period. A set of 3 five-port valves (Numatics ${ }^{\mathrm{TM}}$ part \# TM101V24C2), one per layer, each mounted on a single manifold (part \# 51030101ASM) direct sample flows between clusters and GC to enable a cluster to be analysed, whilst a second cluster is being collected, thus permitting continuous collection of ambient air.

On completion of each sampling period (refer to Fig. 2) the 3 five-port valves switch simultaneously to initiate the next sample collection and the filled bags are then sequentially measured through a multi-port stream-selection valve 


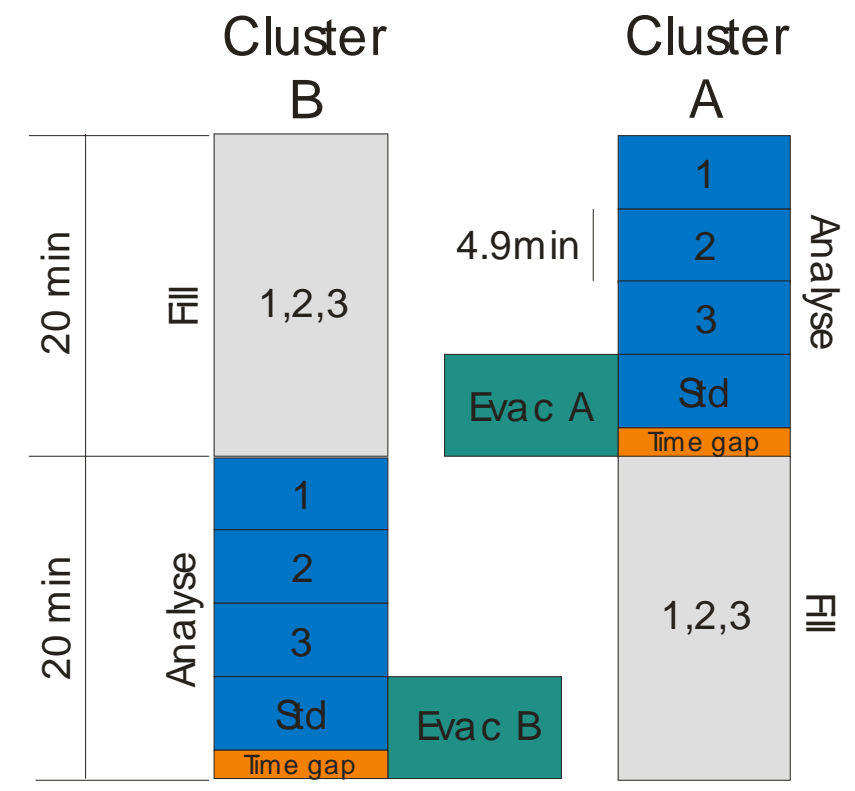

Fig. 2. Sequence control showing alternate filling of one set of bags and simultaneous analysis on the second set of bags. A small time gap after analysis of the standard is required to allow synchronizing to a $20 \mathrm{~min}$ cycle. This achieves continuous integrated sampling over the chosen sampling period.

(VICI model EMT4CSD16MWE) connecting each bag in turn to the inlet of the GC. The sample is drawn from the bag at $100 \mathrm{ml} \mathrm{min}^{-1}$ using a diaphragm pump (KNF model UNMP830 BLDC) and dried to a dewpoint of $-60^{\circ} \mathrm{C}$ before analysis, using a back-flushed Nafion drying tube followed by $1 \mathrm{~g}$ of granulated magnesium perchlorate contained in a glass tube. The drawn sample first flushes the GC sample loop(s) for $30 \mathrm{~s}$, then is relaxed for $10 \mathrm{~s}$ before analysis of the target gases by GC. Following analysis, the bags and sample transfer lines are completely evacuated before starting the next cycle of filling. Figure 2 shows the timing of events as controlled by the LabVIEW program.

\subsection{Application to micrometeorological $\mathrm{N}_{2} \mathrm{O}$ measurement}

The GC determinations of $\mathrm{N}_{2} \mathrm{O}$ and $\mathrm{CO}_{2}$ are carried out using an Agilent 6890 gas chromatograph with electron capture and flame ionisation detectors (ECD and FID), in parallel. Approximately $4 \mathrm{ml}$ aliquots are injected onto two similar but independent GC separation columns. For $\mathrm{N}_{2} \mathrm{O}$, separation is achieved using a $4 \mathrm{~m} \times 3 \mathrm{~mm}$ OD Porapak-Q packed column (80/100 mesh, Alltech) paired with a $2 \mathrm{~m}$ pre-column of the same material. Carrier gas is P-10 mix (10\% methane in argon) at about $30 \mathrm{ml} \mathrm{min}^{-1} \cdot \mathrm{CO}_{2}$ separation is also achieved using a similar $4 \mathrm{~m} \times 3 \mathrm{~mm}$ OD Porapak-Q packed column (80/100 mesh, Alltech) paired with a $2 \mathrm{~m}$ pre-column of the same material. Carrier gas is $\mathrm{N}_{2}$ at about $30 \mathrm{ml} \mathrm{min}^{-1}$. After $\mathrm{CO}_{2}$ is separated from the air components it is then quantitatively reduced to methane on a nickel catalyst (Agilent Technologies) at $400^{\circ} \mathrm{C}$ in $\mathrm{H}_{2}$ and detected by a flame ionisation detector (FID) (Weiss, 1981). The precision of the measurements in the field is $0.3 \mathrm{ppb}(>0.09 \%)$ and $0.1 \mathrm{ppm}$ ( $>0.03 \%$ ) for $\mathrm{N}_{2} \mathrm{O}$ and $\mathrm{CO}_{2}$, respectively. Other gases, or gas combinations, can also be measured if the GC is set up appropriately (see Sect. 4).

Figure 2 shows the sequence control. Within a 20-min cycle, a cluster of bags from the three collection points is measured sequentially along with a calibrated high-span standard gas mixture. The sequence (standard - sample 1 - sample 2 - sample 3) is repeated every twenty minutes, with the three samples alternating between the two clusters; while one cluster is available for analysis, the other is collecting three concurrent samples. The repeated analysis of the working gas standard enables any drift in instrument response caused by external factors, such as room temperature variation, to be captured and compensated for. In this experiment only the 2 inlets in common with the TDL are used in the comparison.

\subsection{Calibration}

The ECD non-linear calibration for $\mathrm{N}_{2} \mathrm{O}$ is based on a suite of six NIWA primary reference standards in aluminium 30 litre cylinders (Scott Marrin Inc., Riverside, CA.) of $\mathrm{N}_{2} \mathrm{O}$ in ultra-high purity UHP air spanning a mixing ratio range of 305 to $355 \mathrm{ppb}$. These are prepared by Scott Specialty Gases and are calibrated at the Scripps Institution of Oceanography, La Jolla, CA. to the SIO-1998 scale (World Meteorological Organisation, 2010). As the FID response to $\mathrm{CH}_{4}$ is highly linear, only two reference standards of 365 and 420 ppm $\mathrm{CO}_{2}$ are used. These are calibrated against the Scripps Institution of Oceanography $\mathrm{CO}_{2}$ mole fraction WMO-X2007 scale (World Meteorological Organisation, 2010). In addition two working standards are prepared in-house:

1. clean air at $317 \mathrm{ppb} \mathrm{N}_{2} \mathrm{O}$, collected at the National Institute of Water and Atmosphere's sampling station at Baring Head, near the entrance to Wellington Harbour (Lowe et al., 1994; Currie et al., 2009);

2. a mixture amended with extra $\mathrm{N}_{2} \mathrm{O}$ to achieve $355 \mathrm{ppb}$ (high-span standard gas).

Both working standards have been subjected to rigorous and repeated checking against the six NIWA primary standards.

A power law fit describes the response of the ECD over the range $305-355 \mathrm{ppb}$.

$C=C_{0}\left(A / A_{0}\right)^{n}$

Where:

$C$ is the unknown concentration.

$C_{0}$ is the assigned concentration of the working standard. 
$A / A_{0}$ is the ratio of chromatogram area of the sample to that of the working standard.

$n$ is the power-law fit of the curve, determined from the 6 primary standards.

Accuracy of the $\mathrm{N}_{2} \mathrm{O}$ determination is maintained by careful comparison of the working standards against the six primary references used to relate the calibration curve to the SIO-1998 scale. Precision is achieved by running the working standards at a high enough frequency to track instrumental response to environmental factors. Typical precision (std. dev.) of a set of $\left[\mathrm{N}_{2} \mathrm{O}\right]$ determinations in the laboratory is $\pm 0.15 \mathrm{ppb}$. This precision degrades slightly to between 0.2 and $0.3 \mathrm{ppb}$ under field conditions. The minimum detectable flux is given in Table 1. Following the study of Laubach and Kelliher (2004), the precision for flux measurement by the flux-gradient methodology applied in the case study presented here is likely to be of the order of $20 \%$. However, in the following results, we show that there are no systematic biases in concentration difference for the Lung system compared against an independently calibrated tuneable diode laser (TGA-100A, Campbell Scientific, Inc, Logan Utah) flux system run alongside with identical flux footprint. A detailed analysis of alternative micrometeorological protocols is presented by Denmead (2008). Where multigas species analysis is possible, an additional well-calibrated release of a tracer can further improve measurement accuracy. For example, a determination of methane emissions has achieved a flux measurement error of the order of $5 \%$ (Griffith et al., 2008).

\subsection{Field deployment}

For on-farm deployment, we used a purpose-built mobile trailer laboratory fitted with benches along two sides for the Lung -GC system and other equipment, and with ports to allow cabling and tubing entry from outside. The light-weight trailer is easily towed by any medium-sized utility or 4WD vehicle. The trailer is supplied with mains electricity (240V AC) which also powers an air-conditioning unit to maintain a stable interior temperature and humidity environment. Calibration gases are stored inside under the benches and the larger carrier-gas cylinders are kept in a rack outside.

The laboratory was located so as not to disturb air-flow to the instrumented mast which is positioned near the centre of the study area and up to $200 \mathrm{~m}$ from the laboratory (the practical maximum length of the airlines). Site selection is guided by the usual practical aspects of good exposure, avoiding the shelter by trees or buildings in those prevailing wind directions. Once a site and upwind source footprint are selected and instrumentation set up for downwind sampling (e.g. Vesala et al., 2008), the system can be left for day long periods to run automatically. The mast and allied instruments were protected from livestock with a portable electric fence unit; the airlines between the mast and trailer were run inside insulated conduit, or elevated and protected by electric fencing. Routing tubing in this way minimises the likelihood of condensation in the lines when ground temperatures are lower than the air temperature. Once set up, the system can operate unattended for up to one week, incorporating automatic back-up of data. Downloading and checking of data are carried out daily, achievable via telephone link, cellular or satellite internet telemetry. On-site or remote monitoring of data ensures that any problems are rapidly identified for remedy. With repeated inflation and deflation, the Tedlar bags can be prone to failure. Initially the Tedlar bags developed leaks after a few days operation; these formed at stress points or creases created by repetitive inflation and deflation cycles. This problem has been largely eliminated by fitting a reinforcing rib made from thin polythene tubing to each side of the bags, seen as a ring around the suspended bags in Fig. 3 . In continuous operation, the system has proven to be highly reliable and failures are rare within several weeks continuous sampling. Whilst we are using Tedlar sampling bags in this application, there is a range of alternative flexible polymer and foil film gas sampling bags that could be used. As a prerequisite, any bag needs to be tested for absence of chemical interference (inertness) in the trace gas analysis being performed in addition to considering its durability. A simple rack to hold the bags was developed to prevent airlines tangling during inflation and deflation (Fig. 3). To minimize the requirement for compressed gas cylinders in the field a small electrolytic generator could produce hydrogen for the gas chromatograph, and a zero air generator could supply high purity air to support the flame.

\section{Field trial results and comparison to real-time TDL flux system}

The Lung system was deployed on an irrigated dairy farm in North Canterbury, New Zealand in conjunction with a tuneable diode laser (TDL) instrument for paddock-scale $\mathrm{N}_{2} \mathrm{O}$ flux measurements (Harvey et al., 2008); one goal of this campaign was to compare the automated Lung with the TDL, both applying the gradient technique to infer fluxes of $\mathrm{N}_{2} \mathrm{O}$. The gas handling and calibration systems of the two instruments were completely independent, although the air inlets were co-located. For micrometeorological flux-gradient work, there is a trade-off between the desire to keep the inlet heights close together, in order that each inlet samples gas from a similar upwind fetch, and far enough apart so that within the constraints of measurement precision, the measured concentration differences between heights are large enough to determine.

Measurements were made from a $3 \mathrm{~m}$ micrometeorological mast located in an open paddock on the farm before, during and after grazing episodes by 718 dairy cows. The TDL measurements were made by sampling dried air from 
Table 1. Summary of instrument specifications.

\begin{tabular}{llll}
\hline Technique & Operating set-up & $\begin{array}{l}\text { Gradient precision: } \\
\left(\mathrm{ppb} \mathrm{N}_{2} \mathrm{O}\right)\end{array}$ & $\begin{array}{l}\text { Minimum detectable flux } \\
\left(\mathrm{ng} \mathrm{m}^{-2} \mathrm{~s}^{-1}\right)\end{array}$ \\
\hline Tunable diode laser TGA100 & Gradient - flow through cell & \pm 0.01 & $\begin{array}{l}\text { Best } \sim 3 \\
\text { Typically }<10 \\
\text { Best } \sim 50 \\
\text { Typically }<180\end{array}$ \\
ECD/Gas chromatograph & Gradient - with Tedlar bag accumulator & $\pm 0.2-0.5$ & $\begin{array}{l} \\
\end{array}$ \\
\end{tabular}

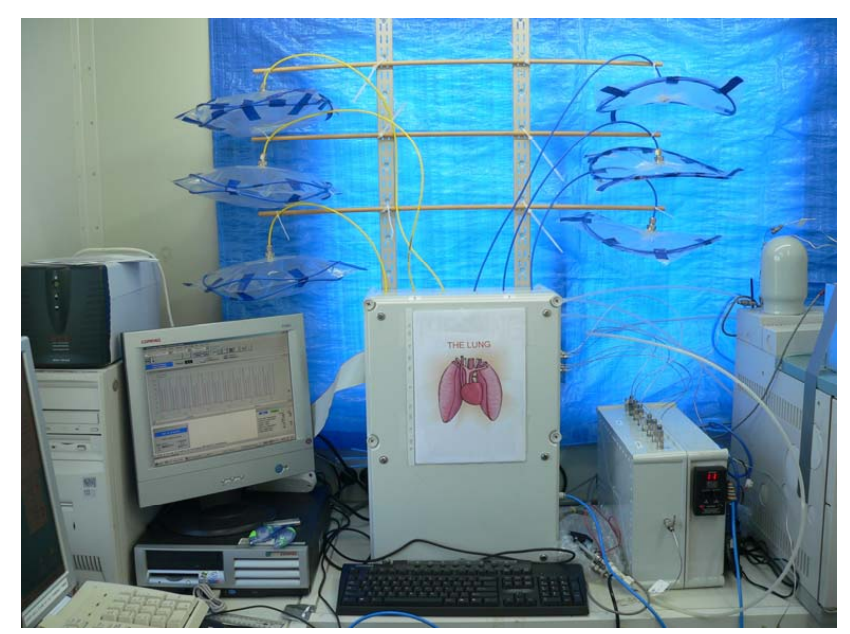

Fig. 3. "Lung-GC system" set-up in mobile laboratory trailer. The "Lung" is in the centre of the picture and corresponds to the shaded box in Fig. 1. The set of bags on the left (Cluster B) are being filled while those on the right (Cluster A) are being evacuated. Ribs on the bags help to keep them flat. To the right of The Lung is the Valco stream selection valve (mounted inside the box) and further to the right the GC can just be seen. To the left of the Lung is the GC control and acquisition PC and the LabVIEWPC controlling the entire process.

two heights ( $2.75 \mathrm{~m}$ and $1.75 \mathrm{~m}$ above ground level) consecutively through switching at 6-s intervals into a common inlet tube of $\sim 100 \mathrm{~m}$ length linking the micrometeorological mast to the analyzer. Gas flow along the inlet tube was sufficiently high $\left(121 \mathrm{~min}^{-1}\right)$ to ensure (turbulent) piston-flow and confined mixing between the 6-s pulses to less than $1 \mathrm{~s}$. Accordingly, a 1-s exclusion period centred on each gas change-over enabled the remaining 5-s pulses to retain their full integrity. $\mathrm{N}_{2} \mathrm{O}$ measurements were made at a rate of $10 \mathrm{~Hz}$ and concentration values were subsequently averaged over a $20 \mathrm{~min}$ period. Air from the same inlet heights as the TDL was dried and sampled continuously over the same 20 -min period and then analysed through the Lung interface, using only two of the three possible Lung inlets. A summary of instrument specifications is given in Table 1 .

The emission flux was estimated using the flux-gradient method (Denmead, 2008) where emission flux $F\left(\mathrm{ngN}_{2} \mathrm{O}-\right.$
$\left.\mathrm{N} \mathrm{m}^{2} \mathrm{~s}^{1}\right) F=k \frac{\Delta C}{\Delta z}$ is the product of eddy diffusivity of the gas $k$ and the difference in dried-air gas concentration $\left(\mathrm{ngN}_{2} \mathrm{O}-\mathrm{N} \mathrm{m}^{-3}\right)$ between the two measurement heights. The calculation of $k$ was made from both 3-D sonic anemometry measurements of wind and an vertical array of cup anemometers incorporating the atmospheric stability corrections, e.g. as described by Hargreaves et al. (1996).

In effect, we are comparing the ability of two systems to measure a concentration difference (gradient) between pairs of samples to high precision. The TDL detector can measure absolute concentrations to only modest accuracy but relative concentration to high precision, while the GC/ECD detector measures concentrations to high accuracy and relative concentrations then follow by difference which for small differences can lead to poor precision.

The time-series of $\mathrm{N}_{2} \mathrm{O}$ vertical concentration difference for the measurement period is shown in Fig. 4. The GC/ECD and TDL measurements show excellent agreement. One characteristic is the larger scatter in $\Delta\left[\mathrm{N}_{2} \mathrm{O}\right]$ of the less precise GC compared to the TDL though both instruments tracked the averaged $\Delta\left[\mathrm{N}_{2} \mathrm{O}\right]$ closely, leading to a consistent concentration gradient. This consistency extended to times of emission bursts that gave rise to a large $\Delta\left[\mathrm{N}_{2} \mathrm{O}\right]$. Figure 5 compares the simultaneously recorded concentration differences of the two independent (TDL and GC) systems for the entire 20-day measurement period of Fig. 4. The differences are plotted on logarithmic scales to show the detail for small concentration differences. For $\Delta \mathrm{N}_{2} \mathrm{O}$ of more than $1 \mathrm{ppb}$ agreement is excellent and relative error small with only 1 or 2 outliers. It is clear from the figure that there are no systematic biases in $\Delta \mathrm{N}_{2} \mathrm{O}$ concentration differences determined by the two instruments. The majority of between instrument difference falls within $\pm 0.5 \mathrm{ppb} \mathrm{N}_{2} \mathrm{O}$, i.e. they are close to the estimated measurement precision of the less precise Lung system.

The estimate of $\mathrm{N}_{2} \mathrm{O}$ emission flux based on the measured $\Delta \mathrm{N}_{2} \mathrm{O}$ is shown in Fig. 6 along with rainfall and irrigation water input measured within $200 \mathrm{~m}$ of the gas measurement mast. These data are presented as six hourly averages each comprising 18 individual gradient-based estimates using 20min data collections. Although we do not focus on understanding the emission process in this paper, we can comment that in general, the figure shows the immediate effect of cattle 


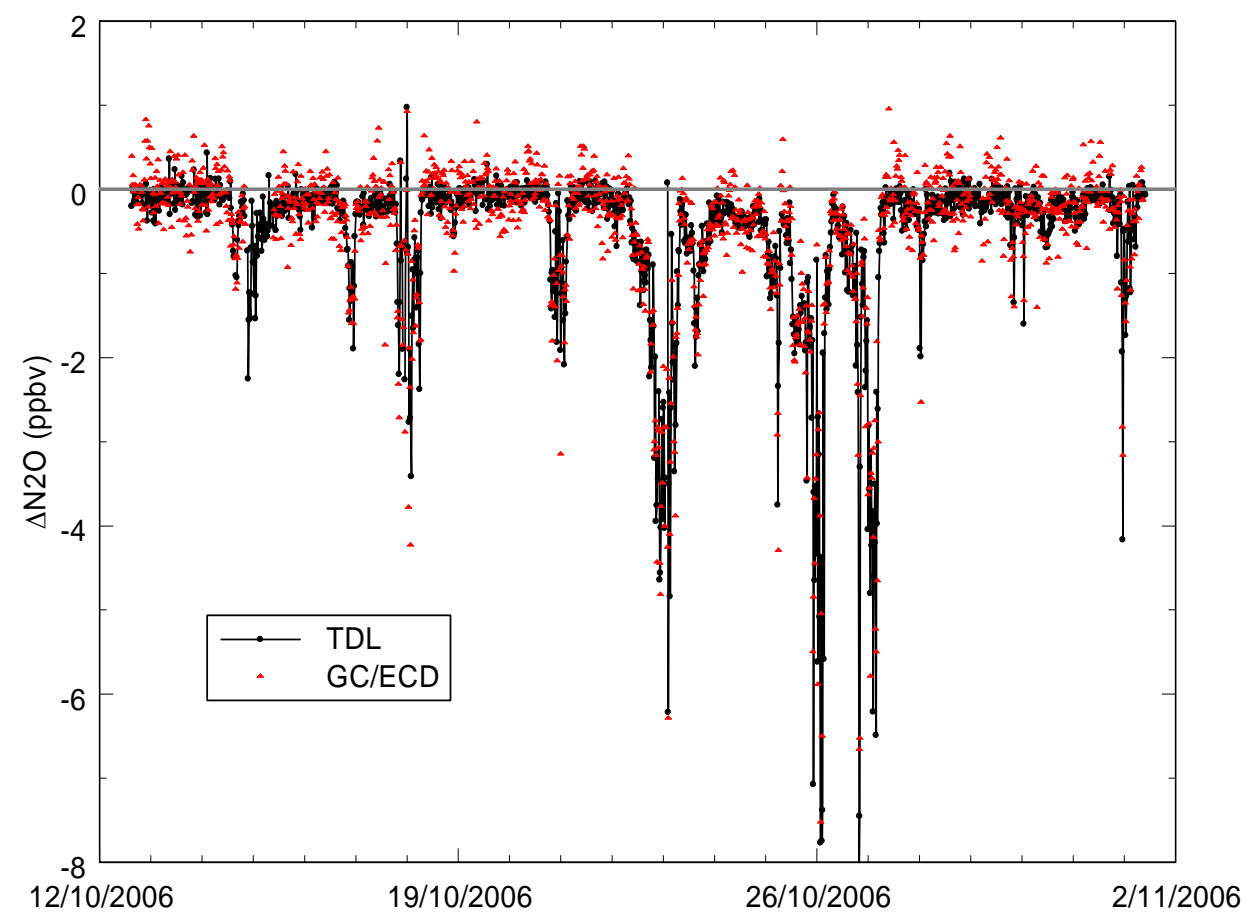

Fig. 4. Timeline of $\mathrm{N}_{2} \mathrm{O}$ vertical gradient mixing ratio difference for TDL and GC.

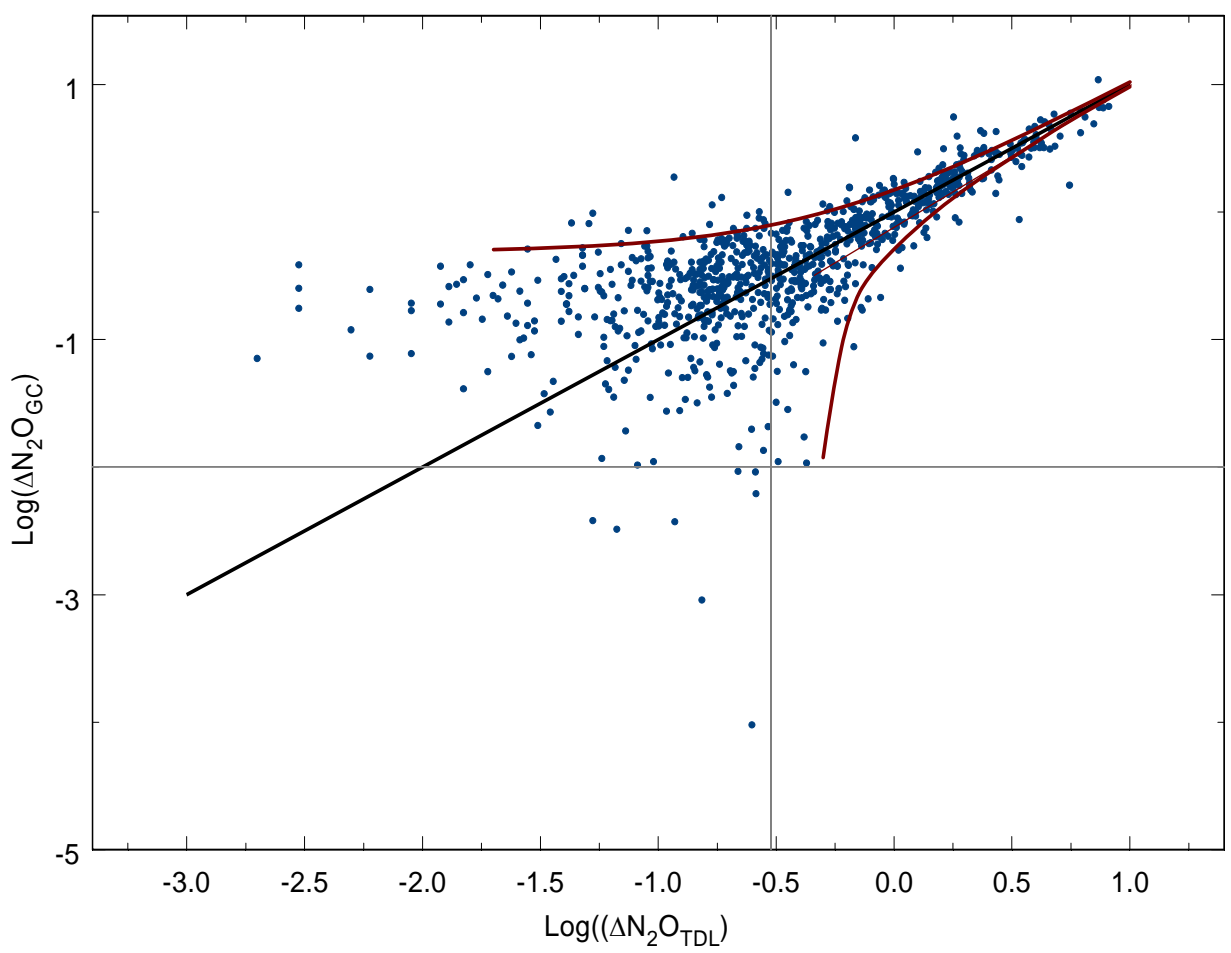

Fig. 5. Scatter plot comparison between the Log (of ppb) TDL-based difference $\Delta \mathrm{N}_{2} \mathrm{O}_{\mathrm{TDL}}$ and GC-based difference $\Delta \mathrm{N}_{2} \mathrm{O}_{\mathrm{GC}}$ in $\mathrm{N}_{2} \mathrm{O}$ mixing ratio. The diagonal line shows $1: 1$ relationship. The precision level of the TDL $(0.01 \mathrm{ppb})$ and GC based system $(0.3 \mathrm{ppb})$ are shown by vertical and horizontal lines, respectively. The curved lines show an envelope of $\pm 0.5 \mathrm{ppb}$ on the GC values. 


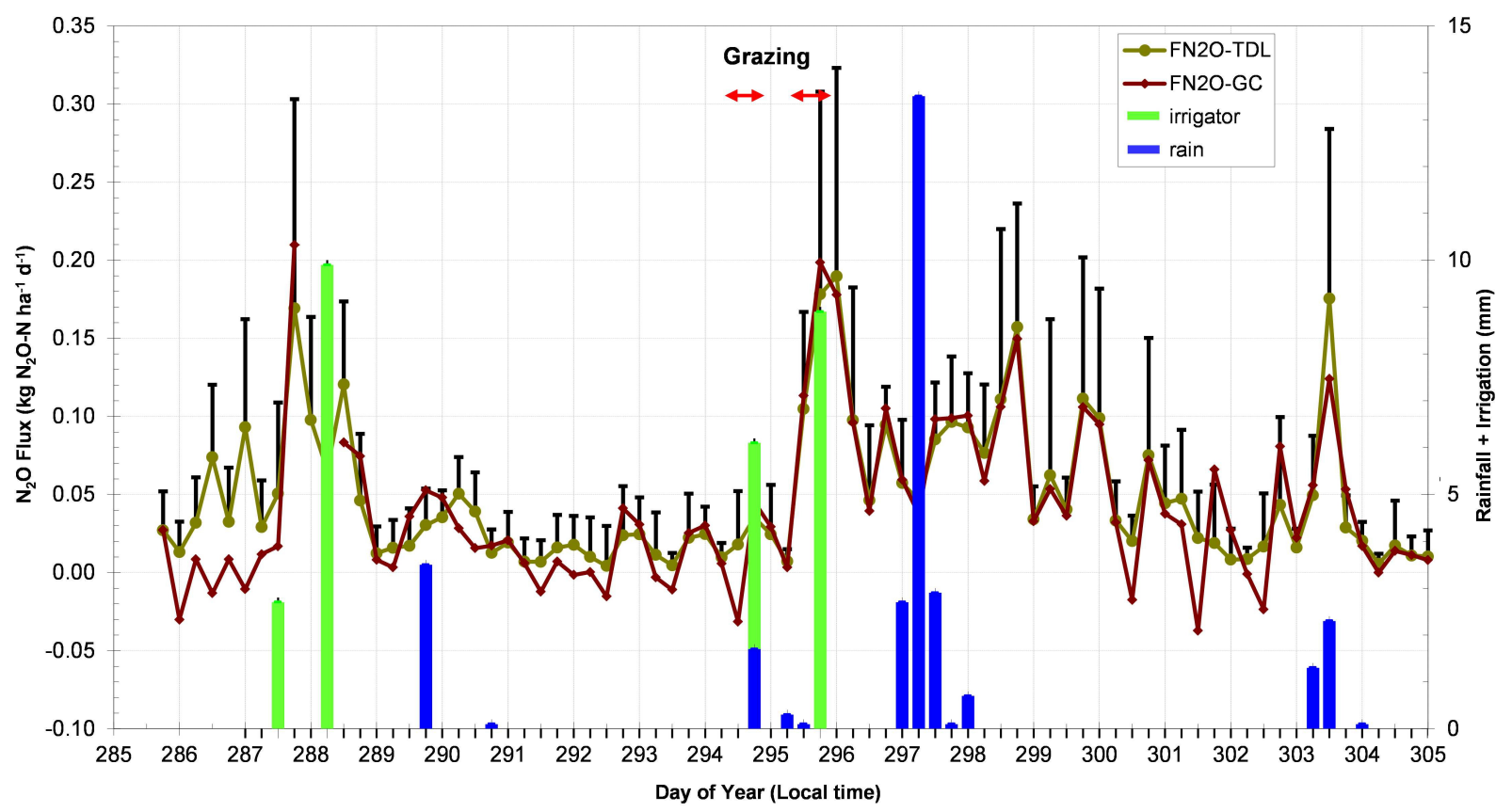

Fig. 6. Gradient flux estimates over 20 days with a grazing event in the middle. Each data point is the averaged emission flux for a 6 hourly period. Error bars are the standard deviation based on individual $20 \mathrm{~min}$ micrometeorological runs. Concurrent 6 hourly totals of natural and irrigator rain input are shown. A period of cattle grazing in the middle of the measurement period is marked.

Table 2. Comparison of TDL and GC flux measurement statistics (Harvey et al., 2008).

\begin{tabular}{lllll}
\hline Instrument & $\begin{array}{l}\text { Median Emission } \mathrm{F}_{\mathrm{N}_{2} \mathrm{O}-\mathrm{N}} \\
\left(\mathrm{kgNha}^{-1} \text { in 10 days) }\right.\end{array}$ & $\begin{array}{l}\text { Mean Emission } \mathrm{F}_{\mathrm{N}_{2} \mathrm{O}-\mathrm{N}} \\
\left(\mathrm{kgNha}^{-1} \text { in 10 days }\right)\end{array}$ & $\begin{array}{l}\mathrm{Std} \text { dev } \mathrm{F}_{\mathrm{N}_{2} \mathrm{O}-\mathrm{N}} \\
\left(\mathrm{kgNha}^{-1} \text { in 10 days }\right)\end{array}$ & $\begin{array}{l}\text { Proportion of time for } \\
\text { highest 50\% emission }\end{array}$ \\
\hline TDL (PreGraze) & 0.19 & 0.34 & 0.50 & $13 \%$ \\
TDL (PostGraze) & 0.32 & 0.57 & 0.73 & $10 \%$ \\
GC (PreGraze) & 0.09 & 0.21 & 0.88 & $10 \%$ \\
$\mathrm{GC}$ (PostGraze) & 0.31 & 0.55 & 0.93 & $9 \%$ \\
\hline
\end{tabular}

grazing with the emissions significantly elevated for at least 6 days following the cattle grazing. This is due to protracted emissions that result from deposited excrement, especially urine. Also of note are the significant emission episodes that lasted from several hours to half a day, following rain or irrigation. Summary statistics of the gradient flux data are given in Table 2. There is excellent agreement between the two instruments, following from the good agreement in the $20 \mathrm{~min}$ mixing ratio data shown in Fig. 4.

In addition to the important emission episodes, the level of agreement between the GC and TDL during a period of low emission is illustrated in Fig. 7. This shows a 3-day pre-grazing period at Days 291-294 (1821 October) when emissions could be considered as baseline. The $\Delta \mathrm{N}_{2} \mathrm{O}$ assessed by the TDL for this period was $-0.076 \pm 0.118 \mathrm{ppb}$ (mean \pm s.d.). The average of the $\Delta \mathrm{N}_{2} \mathrm{O}$ determined by GC was within 0.3 standard deviations of this at $-0.044 \pm 0.274 \mathrm{ppb}$. It is during periods of low emission that the Lung-GC system is most challenged by its lesser precision. In particular there is a tendency for negative (uptake) fluxes to be estimated, though not significant, in the 20 min data because of the lower precision or greater noise in the sampling period. This negative flux is observed much less frequently in the TDL with its higher precision. Whilst it has been suggested that soil may occasionally act as a sink for $\mathrm{N}_{2} \mathrm{O}$ (Chapuis-Lardy et al., 2007; Flechard et al., 2005), it is unproven in this relatively nitrogen-rich soil environment, though might occur in localised patches of relative nitrogen impoverishment. Overall, there is good agreement in the upscaled Lung-based flux estimate (see Table 2). With the apparent negative flux excursions at times of low emission for the pre-grazing periods, the GC underestimates the smaller flux by around $40 \%$ relative to the TDL. However, during periods of high emission and for the whole post-grazing period, the Lung-GC based flux estimate was, remarkably, within $3 \%$ of the TDL estimate over the $\sim 10$ day assessment period. 


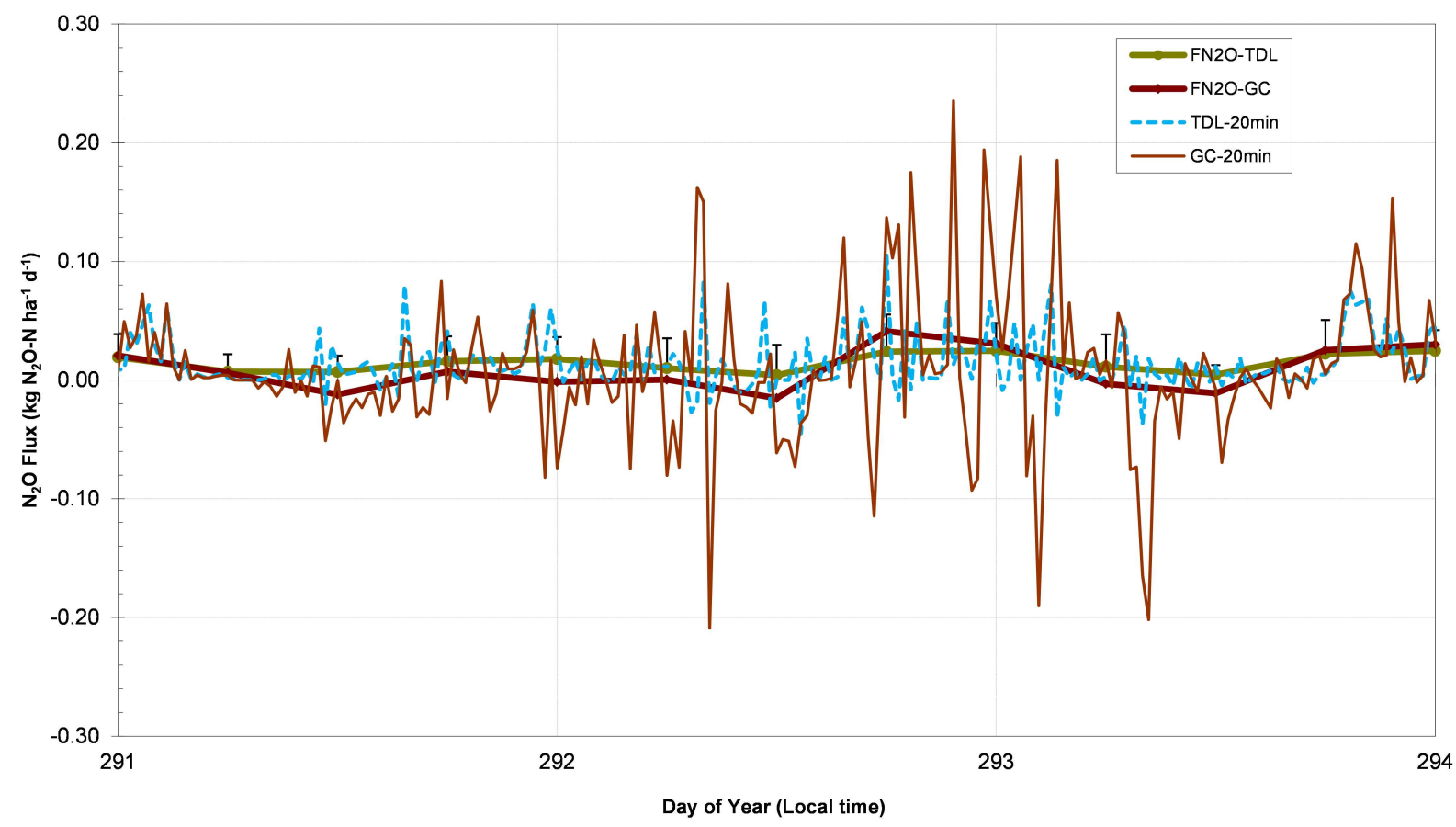

Fig. 7. Comparison of $20 \mathrm{~min}$ and 6 hourly averaged fluxes from Fig. 6 during a baseline (quiescent) period for emission.

\section{Other Lung applications}

The Lung system has a wide range of other possible applications beyond multiple heights on a single mast, where on-line continuous and concurrent measurement is required from different sampling points. In 2005 a prototype Lung measured atmospheric methane continuously for a two-month period in a rural setting to gather "background" trace-gas data for use in mesoscale meteorological and dispersion models, and to interpret temporal patterns of agricultural emissions. A similar design of bag accumulator system with a single bag set has been deployed in a long-term micrometeorological experiment by (McMillan et al., 2007) to investigate $\mathrm{CH}_{4}$ and $\mathrm{CO}_{2}$ exchange with a rice paddy. In addition to micrometeorological applications, the Lung system was used in 2009 to continuously monitor breath emissions concurrently from three penned sheep over a six week period in a study which used $\mathrm{SF}_{6}$ as a tracer to examine the variability in methane emission rates by ruminant animals (Lassey et al., 2011). The Lung could be deployed to determine greenhouse gas emissions from animal enclosures, such as from barns (Marik and Levin, 1996; Kaharabata et al., 2000), feedlots or pens, or from whole-animal respiratory chambers, for which a purposeful tracer such as $\mathrm{SF}_{6}$ could be deployed and detected (e.g. McGinn et al., 2006; Grainger et al., 2007). With the modification from concurrent to sequential collection into 3 bags, a related design of automated bag accumulator has recently been suggested by Ambus et al. (2010) for measuring flux from integrating multiple sequences of concentration build-up in a soil autochamber system. The Lung also has the potential for use in detecting various gases in a wide range of non-agricultural settings such as in urban air quality studies, biogenic emissions from pine forests or oceans (Zemmelink et al., 2002), and methane emissions from wetland areas or from landfill sites.

The choice of 3 inlets and a $20 \mathrm{~min}$ cycle time for the Lung is dictated by (a) the fact that 3 inlets is often sufficient, (b) the elution time of the GC and (c) the desired sample integration time. The system is modular and it is quite feasible to design more inlets if the relevant elution times are short or a fast analyser used.

\section{Conclusions}

The "Lung" sampling system with its coupled gas chromatograph has been shown to be a simple, non-intrusive way of measuring greenhouse gas fluxes continuously at the paddock scale, compared with a soil chamber system where air circulation and gas concentration immediately above the soil surface is perturbed (Rochette, 2011). This paper demonstrates the capability for $\mathrm{N}_{2} \mathrm{O}$ but simultaneous measurements of $\mathrm{CH}_{4}, \mathrm{~N}_{2} \mathrm{O}$ and $\mathrm{CO}_{2}$ would be possible using standard chromatographic equipment that is readily available in most gas analysis laboratories. A remarkably good agreement with the high-precision results obtained from the TDL can be achieved, though as a result of its lower precision in $\Delta \mathrm{N}_{2} \mathrm{O}$ determinations, the Lung-GC system is subject to larger errors in flux determination during periods of very low emission. 
In a field inter-comparison of the Lung-GC system and TDL instrument, we have obtained good agreement in characterising the $\mathrm{N}_{2} \mathrm{O}$ flux. The field site comprised a dairy paddock with episodic emissions characterized by events of high emission lasting several hours punctuating longer periods at "baseline" levels; the continuous measurements by the Lung system is able to capture these emission episodes that could be missed by static chamber deployment. During the campaign reported here and elsewhere (Harvey et al., 2008; Saggar et al., 2010) the highest $50 \%$ of emissions were found to occur in $10 \%$ of the elapsed time. For accurate assessment of emissions that are highly episodic and spatially heterogeneous such as can be the case with nitrous oxide, continuous and spatially-integrating measurement is critical to capturing such episodes and heterogeneities. Under these circumstances, a manual chamber sampling programme may miss a significant proportion of the emission. The error in emission estimate made by missing the emission episodes is greater than the accuracy limitations of the micrometeorological techniques.

Acknowledgements. The authors acknowledge Keith Lassey (NIWA) for helpful comments on preparing the manuscript and as an internal reviewer.

The work was funded by through MRST CRI Capability Fund contract "New technologies for on-farm greenhouse gas emission assessment and mitigation studies", and the Foundation for Research Science and Technology Public Good Science Fund under contracts CO9X0212 "Reducing Greenhouse Gas Emissions from the terrestrial biosphere", Landcare Research and CO1X0204 "Drivers and Mitigation of Global Change", NIWA. Field work was made possible through the kind support of the owners and management of Medcroft Dairy Farm.

Edited by: J.-P. Putaud

\section{References}

Ambus, P., Skiba, U., Drewer, J., Jones, S. K., Carter, M. S., Albert, K. R., and Sutton, M. A.: Development of an accumulation-based system for cost-effective chamber measurements of inert trace gas fluxes, Eur. J. Soil Sci., 61, 785-792, doi:10.1111/j.1365-2389.2010.01272.x, 2010.

Chapuis-Lardy, L., Wrange, N., Metay, A., Chotter, J.-L., and Bernoux, M.: Soils, a sink for $\mathrm{N}_{2} \mathrm{O}$ ?, A review, Global Change Biol., 13, 1-17, doi:10.1111/j.1365-2486.2006.01280.x, 2007.

Currie, K. I., Brailsford, G., Nichol, S., Gomez, A., Sparks, R. J., Lassey, K. R., and Riedel, K.: Tropospheric ${ }^{14} \mathrm{CO}_{2}$ at Wellington, New Zealand: the world's longest record, Biogeochem., 104, 522, doi:10.1007/s10533-009-9352-6, 2009.

Davidson, E. A., Savage, K., Verchot, L. V., and Navarro, R.: Minimising artifacts and biases in chamber-based measurements of soil respiration, Agric. For. Meteorol., 113, 21-37, 2002.

Denmead, O. T.: Approaches to measuring fluxes of methane and nitrous oxide between landscapes and the atmosphere, Plant. Soil, 309, 5-24, 2008.
Eugster, W. and Plüss, P.: A fault-tolerant eddy covariance system for measuring $\mathrm{CH}_{4}$ fluxes, Agric. For. Meteorol., 150, 841-851, doi:10.1016/j.agrformet.2009.12.008, 2010.

Flechard, C. R., Neftel, A., Jocher, M., Ammann, C., and Fuhrer, J.: Bi-directional soil/atmosphere $\mathrm{N}_{2} \mathrm{O}$ exchange over two mown grasland systems with contrasting management practices., Global Change Biol., 11, 2114-2127, doi:10.1111/j.13652486.2005.01056.x, 2005.

Grainger, C., Clarke, T., McGinn, S. M., Auldist, M. J., Beauchemin, K. A., Hannah, M. C., Waghorn, G. C., Clark, H., and Eckard, R. J.: Methane emissions from dairy cows measured using sulfur hexafluoride (SF6) tracer and chamber techniques, J. Dairy Sci. 90, 2755-2766, 2007.

Griffith, D. W. T., Bryant, G. R., Hsu, D., and Reisinger, A. R.: Methane emissions from free-ranging cattle: Comparison of tracer and integrated horizontal flux techniques., J. Environ. Qual., 37, 582-591, 2008.

Hargreaves, K. J., Wienhold, F. G., Klemedtsson, L., Arah, J. R. M., Beverland, I. J., Fowler, D., Galle, B., Griffith, D. W. T., Skiba, U., Smith, K. A., Welling, M., and Harris, G. W.: Measurement of nitrous oxide emission from agricultural land using micrometeorological methods, Atmos. Environ., 30, 1563-1571, 1996.

Harvey, M., Pattey, E., Saggar, S., T., B., Dow, D., Kotkamp, M., Martin, R., Moss, R., and Singh, J.: Verification techniques for $\mathrm{N}_{2} \mathrm{O}$ emission at the paddock scale in New Zealand: FarmGas 2006, Aust. J. Exp. Agric., 48, 138-141, 2008.

Johnson, K., Huyler, M., Westberg, H., Lamb, B., and Zimmerman, P.: Measurement of methane emission from ruminant livestock using a $\mathrm{SF}_{6}$ tracer technique, Environ. Sci. Technol., 28, 359362, 1994.

Kaharabata, S. K., Schuepp, P. H., and Desjardins, R. L.: Esimating methane emissions from dairy cattle housed in a barn and feedlot using an atmospheric tracer., Environ. Sci. Technol., 34, 32963302, 2000.

Kroon, P. S., Hensen, A., Jonker, H. J. J., Ouwersloot, H. G., Vermeulen, A. T., and Bosveld, F. C.: Uncertainties in eddy covariance flux measurements assessed from $\mathrm{CH} 4$ and N2O observations, Agric. For. Meteorol., 150, 806-816, doi:10.1016/j.agrformet.2009.12.008, 2010.

Lassey, K. R., Ulyatt, M. J., Martin, R. J., Walker, C. F., and Shelton, I. D.: Methane emissions measured directly from grazing livestock in New Zealand, Atmos. Environ., 31, 2905-2914, 1997.

Lassey, K. R., Pinares-Patiño, C. S., Martin, R. J., Molano, G., and McMillan, A. M. S.: Enteric methane emission rates determined by the $\mathrm{SF}_{6}$ tracer technique: temporal patterns and averaging periods, Anim. Feed. Sci. Tech., 166-167, 183-191, 2011.

Laubach, J. and Kelliher, F. M.: Measuring methane emission rates of a dairy cow herd by two micrometeorological techniques, Agric. For. Meteorol., 125, 279-303, 2004.

Laubach, J., Kelliher, F. M., Knight, T., Clark, H., Molano, G., and Cavanagh, A.: Methane emissions from beef cattle - a comparison of paddock- and animal-scale measurements, Aust. J. Exp. Agric., 48, 132-137, 2008.

Livingston, G. P., Hutchinson, G. L., and Spartalian, K.: Diffusion theory improves chamber-based measurements of trace gas emissions, Geophys. Res. Lett., 32, L24817, doi:10.1029/2005GL024744, 2005.

Lowe, D. C., Brenninkmeijer, C. A. M., Brailsford, G. W., Lassey, 
K. R., and Gomez, A. J.: Concentration and ${ }^{13} \mathrm{C}$ records of atmospheric methane in New Zealand and Antarctica: evidence for changes in methane sources, J. Geophys. Res., 99, 16913-16925, 1994.

Marik, T. and Levin, I.: A new tracer experiment to estimate the methane emissions from a dairy cow shed using sulfur hexafluoride (SF6), Global Biogeochem. Cy., 10, 413-418, doi:10.1029/96gb01456, 1996.

McGinn, S. M., Flesch, T. K., Harper, L. A., and Beauchemin, K. A.: An approach for measuring methane emissions from whole farms, J. Environ. Qual., 35, 14-20, 2006.

McMillan, A. M. S., Goulden, M. L., and Tyler, S. C.: Stoichiometry of $\mathrm{CH}_{4}$ and $\mathrm{CO}_{2}$ flux in a California rice paddy, J. Geophys. Res., 112, G01008, doi:10.1029/2006JG000198, 2007.

Ministry for the Environment: New Zealand's Greenhouse Gas Inventory 1990-2008, ME1009, Wellington, New Zealand, 295, 2010.

Parkin, T. B.: Effect of sampling frequency on estimates of cumulative nitrous oxide emissions, J. Environ. Qual., 37, 1390-1395, doi:10.2134/jeq2007.0333, 2008.

Pattey, E., Edwards, G., Strachan, I. B., Desjardins, R. L., Kaharabata, S., and Wagner Riddle, C.: Towards standards for measuring greenhouse gas fluxes from agricultural fields using instrumented towers, Can. J. Soil Sci., 86, 373-400, 2006.

Pihlatie, M., Rinne, J., Ambus, P., Pilegaard, K., Dorsey, J. R., Rannik, Ü., Markkanen, T., Launiainen, S., and Vesala, T.: Nitrous oxide emissions from a beech forest floor measured by eddy covariance and soil enclosure techniques, Biogeosciences, 2, 377387, doi:10.5194/bg-2-377-2005, 2005.

Pinares-Patiño, C. S. and Clark, H.: Reliability of the sulfur hexafluoride tracer technique for methane emission measurement from individual animals: an overview, Aust. J. Exp. Agric., 48, 223229, doi:10.1071/EA07297, 2008.

Pinares-Patino, C. S., Holmes, C. W., Lassey, K. R., and Ulyatt, M. J.: Measurement of methane emission from sheep by the sulphur hexafluoride tracer technique and by the calorimetric chamber: failure and success, Animal, 2, 141-148, doi:10.1017/S1751731107000857, 2008.

Rochette, P.: Towards a standard non-steady-state chamber methodology for measuring soil $\mathrm{N}_{2} \mathrm{O}$ emissions, Anim. Feed. Sci Tech., 166-167, 141-146, 2011.
Saggar, S., Harvey, M., Singh, J., Giltrap, D., Pattey, E., Bromley, T., Martin, R., Dow, D., Moss, R., and McMillan, A.: Chambers, micrometeorological measurements, and the New Zealand Denitrification \& Decomposition model for nitrous oxide emission estimates from an irrigated dairy-grazed pasture, Journal of Integrative Environmental Sciences, 7, 61-70, 2010.

Smith, P., Martino, D., Cai, Z., Gwary, D., Janzen, H., Kumar, P., McCarl, B., Ogle, S., O’Mara, F., Rice, C., Scholes, B., and Sirotenko, O.: Agriculture, in: Mitigation. Contribution of Working Group III to the Fourth Assessment Report of the Intergovernmental Panel on Climate Change, edited by: Metz, B., Davidson, O. R., Bosch, P. R., Dave, R., and Meyer, L. A., Cambridge University Press, Cambridge, UK and New York, NY, USA, 2007.

Statistics New Zealand: Global New Zealand - International Trade, Investment, and Travel Profile: Year ended June 2009., Statistics New Zealand | Tatauranga Aotearoa, Wellington, 2009.

Suleau, M., Debacq, A., Dehaes, V., and Aubinet, M.: Wind velocity perturbation of soil respiration measurements using closed dynamic chambers, Eur. J. Soil Sci., 60, 515-524, 2009.

Vesala, T., Kljun, N., Rannik, Ü., Rinne, J., Sogachev, A., Markkanen, T., Sabelfeld, K., Foken, T., and Leclerc, M. Y.: Flux and concentration footprint modelling: State of the art, Environ. Pollut., 152, 653-666, 2008.

Weiss, R.: Determinations of Carbon Dioxide and Methane by Dual Catalyst Flame lonization Chromatography and Nitrous Oxide by Electron Capture Chromatography, J. Chromatogr. Sci., 19, 611-616, 1981.

World Meteorological Organisation: Appendix A Calibration and Standard Scales, in: WMO WDCGG Data Summary GAW Data Volume IV- Greenhouse Gases and Other Atmospheric Gases, Japan Meteorological Agency in Co-operation with the World Meteorological Organisation, 2010.

Zemmelink, H. J., Gieskes, W. W. C., Klaassen, W., de Groot, H. W., de Baar, H. J. W., Dacey, J. W. H., Hintsa, E. J., and McGillis, W. R.: Simultaneous use of relaxed eddy accumulation and gradient flux techniques for the measurement of sea-toair exchange of dimethyl sulphide, Atmos. Environ., 36, 57095717, doi:10.1016/s1352-2310(02)00577-0, 2002. 